\title{
Contested Surf Tourism Resources in the Maldives
}

\begin{abstract}
We analyse contests for control of a newly valuable tourism resource, namely surf breaks in the Maldives. Conflicts are shaped by: the resource, economics, culture, legislation, and politics. There are seven stakeholder groups: island resorts, resort-based surfing tourists, liveaboard charter boats, boat-based surfing tourists, local surf-related enterprises, independent travelling surfers using those enterprises, and local resident surfers. We identify a transition from exogenously to endogenously-controlled political processes and power. These are driven by tourism growth, and accelerated by specific trigger events related to political change, land tenure, and development projects. Tourism destinations have seldom been studied in the context of control over natural resources. The transition model constructed here applies across destinations, adventure activities, tourism subsectors, and other industries.
\end{abstract}

Keywords: adventure; property; privatization; land-use; surfing 


\section{INTRODUCTION}

Many tourism subsectors rely on particular sites and their natural resources, and commercial tourism enterprises compete to obtain and/or control access and use of those resources. Such competition may occur through social, economic, administrative or political processes. Here we analyse these processes for a newly valuable and heavily contested tourism resource, namely surf breaks in the Republic of Maldives.

The theoretical framework adopted for this analysis is that of property rights. Property rights are a key but complex component in the structures of most human societies, and in consequence, have been analysed in considerable detail. There are many different types and classifications of property rights (Sikor, He \& Lestrelin, 2017). For example, they may be classified according to the subject of the right, such as land, physical objects, or intellectual property. They may be classified according to the degree of exclusivity and excludability, differentiating open-access, common, public, communal and private rights (Ostrom, 2015). They may be classified according to their social basis, distinguishing traditional or customary from modern legal rights (Murtazashvili \& Murtazashvili, 2016). Or, they may be classified according to the bundle of specific rights included within a particular concept of property, such as rights of access, use, destruction, transfer, trade, lease or sale. These characteristics are commonly cross-linked.

Of particular relevance to this study are the ways in which rights may be defined or reallocated through political interactions between governments, private citizens or corporations, and individuals with customary rights, including those held in common. The degree to which such changes have occurred through political contests, and the consequences for the various stakeholders concerned, have been examined over an extended period, for many different industry sectors and geographical regions (Ahn, Balafoutas, Batsaikhan, Campos-Ortiz, Putterman, \& Sutter, 2016; Buckley, 1994; Grainger \& Costello, 2016; Murtazashvili \& Murtazashvili, 2016; Ostrom, 2015; Sikor et al., 2017; Slaev, 2016; Webster, Wu, Zhang, \& Sarkar, 2016). These analyses note, for example, that there are many instances where locally-recognised historical rights may be changed or coopted as they are incorporated into national-recognised systems, often with deliberate or unintentional economic redistribution effects. They also note that any government powerful enough to enforce property rights is generally also powerful enough to seize them, whether for projects intended to provide public good, or for the private good of corrupt officials or corporations.

Property rights are of major importance in all forms of tourism and recreation, from hunting and harvesting (Øian, \& Skogen, 2016; Sténs \& Sandström, 2013) to international hotel investment (Assaf, Josiassen, \& Agbola, 2015; Balli, Balli, \& Louis, 2016; Lee, 2015). Formal ("bankable") land tenure titles are critical in attracting tourism investment. This applies, for example, in: rural communities with communal titles (Ho, 2013; Lamers, Nthiga, van der Duim, \& van Wijk, J., 2014); rural areas converting from primary production to tourism (Matilainen \& Lähdesmäki, 2014; Roxas \& Chadee, 2013); urban areas with poorly formalised historical ownership systems (Xu, Liu, Qian, \& Wang, 2017); developed nations where property may be held under devolved multi-level ("strata” or "condo") titles (Easthope, Hudson, \& Randolph, 2013); and marine and coastal environments and developments (Kerr, Colton, Johnson, \& Wright, 2015). 
Legal and practical tenure and ownership of valuable natural resources is commonly contested through national or regional scale political means, with many different public, private, and communal ownership models in use worldwide (Ballet, Bazin, Koffi \& Komena, 2015; Colvin, Witt \& Lacey, 2015; Dyer, 2016). To date, these processes have been studied principally for extractive natural resources such as minerals, forests, fisheries, agricultural lands, and water (de Rijke, Munro \& Lourdes, 2016; Derky, Ros-Tonen, Kyereh \& Dietz, 2014; Kitamura \& Clapp, 2013; Moffat, Lacey, Zhang \& Leopold, 2016). In adventure tourism and recreation, in contrast, tenure of most well-established sites is well defined, and conflicts over access are managed largely through local administrative approaches such as recreational capacity measures and site regulations (Buckley, 2015). This applies, for example, to coastal tourism destinations (Lucrezi, Saayman \& van der Merwe, 2015; Navarro-Jurado, Mihada-Damian \& Fernandez-Morales, 2013) and to outdoor recreation in national parks (Leung, Spenceley, Hvenegaard \& Buckley, 2016; Manning, 2007).

Some sites, however, whilst newly valuable for adventure tourism, lack any established legal right or precedent to control recreational access. At such sites, contests over access rights can involve very active local and national-scale social and political conflict (Wan \& Bramwell, 2015; Williams, 2001). These processes are more closely analogous to political conflicts over extractive resources, than to administrative management of recreational capacity at longestablished sites (de Rijke, et al., 2016; Dyer, 2016; Kerr, Colton, Johnson \& Wright, 2015; Omar, Pretsch, \& Darr, 2015). It is these conflicts that we examine here: contests over the ability to control access to sites newly valuable for adventure tourism and recreation. We adopt a broad definition of conflict, as “incompatibilities in stakeholders' interests, values or priorities” (Adams, Brockington, Dyson \& Vira, 2003), including antecedents, context, issues, causes, dynamics, and resolution (Derkyi et al., 2014). We analyse this process using a single adventure tourism activity in a single nation.

The surf tourism sector provides a good model for the analysis of contested site access across the entire adventure and other tourism sectors, for several reasons. First, it is a large and widespread subsector, with 35 million participants in over 160 countries (Martin \& Assenov, 2012; Ponting \& O'Brien, 2014). Second, growth to the current scale has occurred rapidly and recently, during only a few decades (Ponting \& O'Brien, 2014). Third, different sites, known as surf breaks, differ greatly in their attractiveness to surfers. Surf breaks rely on ocean swell exposure and wave climate, and ocean floor topography (bathymetry), to generate a consistent supply of high-quality surfable waves (Hutt, Black, \& Mead, 2001; Scarfe, Healy, \& Rennie, 2009). The size, shape, speed, and consistency of surfing waves differ greatly between surf breaks, and surfers are prepared to invest substantial time, money, and effort to surf the best breaks (Buckley 2002a,b, 2010; Ponting \& O’Brien, 2014; Towner \& Orams, 2016).

Fourth, the number of surfers continues to increase, but the number of surf breaks remains constant, so demand for surf breaks increasingly outstrips supply. Increasing crowding in peri-urban settings drives demand for surf tourism to more remote and less crowded surfing destinations (Buckley, 2002a,b, 2010; Dolnicar \& Fluker, 2003; Martin \& Assenov, 2012; O’Brien \& Ponting, 2013; Ponting \& O’Brien, 2014; Scorse, Reynolds, \& Sackett, 2015; Towner, 2016a,b; Towner \& Orams, 2016). Many of these new surf tourism destinations are in developing nations with no local history of surfing, and hence no prior crowding (O'Brien \& Ponting, 2013). Fifth, however, local residents at some of these sites have indeed become skilled surfers (Buckley \& Ollenburg, 2013; Towner, 2016), so there is now competition for 
access between local resident surfers, and visiting foreign surfers including commercial surf tourism clients. The Republic of Maldives illustrates these factors well.

Sixth, the existence of local-scale conflicts between individual surfers or groups of surfers is well documented, including phenomena such as surf rage and localism, surf fashion and tribalism, and privatization of specific surf breaks (Anderson, 2016; Ball, 2015; Beaumont \& Brown, 2016; Buckley, 2003a; Deats, Martinez, Shearer, \& Shearer, 2016; Usher, Goff, \& Gomez, 2016). Here, however, we take a broader perspective, treating surf breaks as contested tourism resources, and analysing the political and practical processes adopted by competing surf stakeholders.

Whilst the theoretical framework is that of property rights, the methodological approach adopted is a case-study with qualitative data collection and analysis, analogous to the approach used in grounded theory. That is, we identify a specific case study site to test and examine the property-rights framework; compile information from both documentary sources and oral interviews; and analyse documents and interview transcripts using iterative conceptual deconstruction and hierarchical reassembly with both basic and axial coding. Our aim is to determine, within the property rights framework, both what has happened, and how and why.

\section{METHODS}

\subsection{Case Study Approach and Site Selection}

We adopted a qualitative case-study approach (Baxter, 2010; Veal, 2011) as the overall methodological framework, incorporating document analysis, stakeholder interviews, and differential narrative comparisons. These multiple sources of data allowed us to: review relevant aspects of the country's geography, history, politics, culture, and legislation; analyze the development of its surf tourism subsector; identify stakeholder groups and interests; track how groups have formed political alliances to further their own interests; and show how this process affects not only the surf sector, but the entire tourism industry.

The Republic of Maldives was selected as the study site through a purposive process (Gerring, 2007). It has a well-established commercial tourism industry, known particularly as a tropical island beach destination and a specialist dive tourism destination (Buckley, 2003b, 2006, 2010; Scheyvens, 2011; Shakeela \& Weaver, 2012; Anon, 2015; Shakeela \& Becken, 2015). It is also a globally-known surf tourism destination, with a rapidly growing commercial surf tourism sector that is currently competing for access rights to a limited number of high quality waves (Buckley, et al., 2014). Surfing sites within the Maldives are in high demand, and the ability to gain and control access to these sites is newly valuable.

The range of different land tenure systems in the Maldives allows comparison of sites with similar quality surf breaks, but different types of access. Many local residents have become surfers themselves, and some have entered the surf tourism sector as commercial providers, providing additional complexity amongst stakeholders. In addition, the recent social, political and development history of the Maldives provides opportunities to compare time periods with different policies and legislation. 


\subsection{Document analysis}

Relevant documentary information was compiled from both English and Dhivehi sources. One of the authors is bilingual in Dhivehi and English. Documents were identified between July 2014 and July 2016 using standard online search engines. We adopted sequential search strategies, using relevant geographic, activity-based and issue-based search terms.

Geographic search terms included: Maldives and the names of individual atolls, islands, and surf breaks. Activity-based search terms included: surfing, diving, live-aboard, charter boat, resort, lodge, and camp. Issue-based search terms included: ownership, access, tenure, community, local, permit, license, register, lease, conflict, controversy, privatisation, exclusivity, etc. All online sources were cross-referenced and cross-checked to extend and refine searches.

Document types included: academic journal articles; government reports; legislation updates; tourism business prospectuses; press releases and news items from resorts, guesthouses and local Maldivian associations; websites and magazines of commercial surf tourism operators in the Maldives; surfing magazines and online comment threads; news items posted by local and international media outlets; and online multimedia materials (Lamb, 2012; Shenk, 2011). Conflict over access to surf breaks in the Maldives has received considerable attention in the popular and professional surfing literature (Conolly, 2012; Mull, 2012, 2013; Nettle, 2012, 2014). Analysing these controversial cases identifies contested space within the surfscape.

Documents were analysed in three steps. First, they were used to construct a historical, geographic, political and cultural context for the surf tourism sector. Second, they were analysed, in conjunction with interviews, using standard qualitative deconstructionreassembly approaches with open and axial coding (Cope, 2010; Punch, 2014). Third, they were included in stakeholder narrative analysis, outlined below.

\subsection{Stakeholder interviews}

On-site, face-to-face, semi-structured interviews (Dunn, 2010; Punch, 2014; Veal, 2011) were conducted with multiple representatives of each of the identified stakeholder groups. One author took part as a former local resident and government employee, and the others as foreign commercial surf tourism clients. A purposeful and snowball sampling approach was adopted to select interviewees in the field, including representation of both local and international stakeholders. A total of 32 interviews were analysed. Of these, 22 were initially interviewed on-site, with multiple follow-up phone and Skype interviews between August 2014 and January 2016. Materials from 10 additional and recent interviews with local Maldivians and a foreign surf guide were obtained from a video record (Save Thanburudhoo, 2013; https://www.youtube.com/watch?v=idi-4geKDmE). These may be incomplete records, but add to the richness of materials provided by on-site interviews.

Local interviewees included: staff of relevant government departments and agencies; members of governing Councils of individual islands; owners and staff of surf resorts and surf charter boats; owners and staff of local small-scale tourism businesses, such as souvenir shops and budget guesthouses either operational or under construction; and individual local residents. International stakeholders interviewed included: commercial surf guides and surf photographers, with several surfing seasons' experience in the Maldives; individual 
international surfers visiting the Maldives either privately or as commercial surf tourism clients; and surf travel booking consultants. Interviews were conducted according to appropriate cultural norms, and in compliance with approved ethics protocols, ensuring anonymity of all participants (see Acknowledgements). No inducements were used, and interviewers offered no opinions. All interviews were transcribed, and analysed as below.

\subsection{Data analysis}

All materials were analysed initially using standard qualitative approaches, with open coding, deconstruction to smallest-scale concepts, and iterative reassembly to successively higher-tier constructs (Cope, 2010; Punch, 2014). This approach was used to identify the principal driving factors for contest over access to surfing sites, and to distinguish the main stakeholders (Reed, Graves, Dandy, Posthumus, Hubacek, et al., 2009). We then used differential narrative analysis (Wells, 2011), effectively a specialised form of axial coding, to contrast stakeholder perspectives. That is, we used the combined views of each group, determined from interviews and documents, to express how each group perceived its identity, its rights, and its desires; and with what justification.

We were thus able to determine the underlying drivers, and the practical processes, of these contests over access to surfing resources. In particular, we were able to identify specific trigger events that changed stakeholder perspectives and actions, forming part of a broaderscale political process. We therefore analyse these trigger events in detail. We then integrated these steps to a second-tier axial coding stage, to identify the underlying political and social processes driving these changes in stakeholder interests and strategies. We suggest that these processes apply equally to other surf tourism destinations, to other subsectors of nature, eco and adventure tourism, and potentially also to other sectors beyond the tourism industry.

\section{RESULTS}

\subsection{Context \& Stakeholders}

\subsubsection{Geography, Culture, Policy \& Tourism}

The Republic of Maldives is an independent archipelagic nation, straddling the equator to the south of the Indian sub-continent (Figure 1). It incorporates 26 atolls, administered as seven provinces. The ocean area is large, with an exclusive economic zone (EEZ) of $859,000 \mathrm{~km}^{2}$; but land is scarce, with total area $298 \mathrm{~km}^{2}, 0.03 \%$ of the EEZ. The Republic of Maldives is one of the world's lowest-lying countries, with average land elevation $<3 \mathrm{~m}$ above mean sea level. It is thus highly vulnerable to inundation and erosion from extreme weather events and from climate change and sea-level rise (Shakeela \& Becken, 2015).

Of 1192 individual islands in the Maldives, 188 are classed as 'inhabited' and 1004 as 'uninhabited'. The total population of the Maldives is a little over 400,000 (407,660 in 2014; NBS, 2015). Of the 188 inhabited islands, only 2.5\% support populations $>5000$, including the capital-city island of Male, where $38 \%$ of the country's entire population reside. About $60 \%$ of the inhabited islands support populations in the range 1000-5000. The remainder have $<1000$ residents. 
Over the past 40 years, the Maldives' economy has become increasingly dependent on tourism (Kundur, 2012; Shakeela \& Weaver, 2012; Scheyvens, 2011). The tourism sector currently contributes $25 \%$ of GDP and $40 \%$ of government revenue (MoT, 2015b). The first island resorts opened in North Malé Atoll (NMA) in 1972. These had an initial joint capacity of 280 beds, and a total of 1,079 tourists arrived that year (Shakeela et al., 2011). Forty-three years later, total bed capacity in 2015 was 31569, with annual tourism visitation over 600,000 (MoT, 2015b). Current bed capacity includes: 111 resorts, with a joint capacity of 23,917 beds; 9 hotels (1704 beds); 220 guesthouses (3,209); and 161 safari vessels (2739) A further 82 resorts and 7 hotels are under development, with additional bed capacity of 13,067 (MoT, 2015b). Uninhabited islands not leased for resort development or other industries are used by residents of local inhabited islands, under traditional access systems known as varuvaa, goi and faalabba (Naseer, 2006; Kundur, 2012; MoT, 2015b; NBS, 2015).

As in many nations, different governments in the Republic of Maldives have emphasised either top-down (political "right") or bottom-up (political "left") development policies. The former focus on promoting centralisation, large-scale projects and infrastructure, and external capital investment. The latter emphasise distributed benefits, diversification, equity, local employment and entrepreneurial opportunities, and domestic investment. Since the Republic of Maldives gained independence from the UK in 1965, right-wing parties held power from 1965-2008 and 2013-2016, and left-wing parties from 2009-2012. The former promoted tourism development through enclave resorts with long-term leases on previously uninhabited islands. These used foreign capital and resort management, and were designed and operated for maximum cultural separation between Western tourists and Muslim citizens. The latter allowed some relaxation in requirements for cultural separation, and added limited opportunities for Maldives citizens to build and own tourist accommodation on inhabited islands (MTAC, 2012a).

\subsubsection{Surf Tourism Resources}

Surfable waves in the Maldives are restricted to the eastern and southern edges of the atolls, where deep channels cross the outer fringing reefs of individual atolls, with appropriate orientation to ocean swell and prevailing winds. Such channels are few (Figure 1). Surfable conditions are also highly seasonal. High quality waves occur only during a few months of the year, when low-pressure systems in the southern Indian Ocean generate consistent swells. Different regions of the Maldives operate during somewhat different surfing seasons. The Southern Atolls (Figure 1A) are at their best for surfing during March and April, and the Malé Atolls from May to October. The Northern Atolls (Figure 1A) are not used for surfing, since they do not possess suitable sites. 
Figure 1. (A) Maldives atolls and surfing regions, (B) Surf breaks in North Male Atoll.

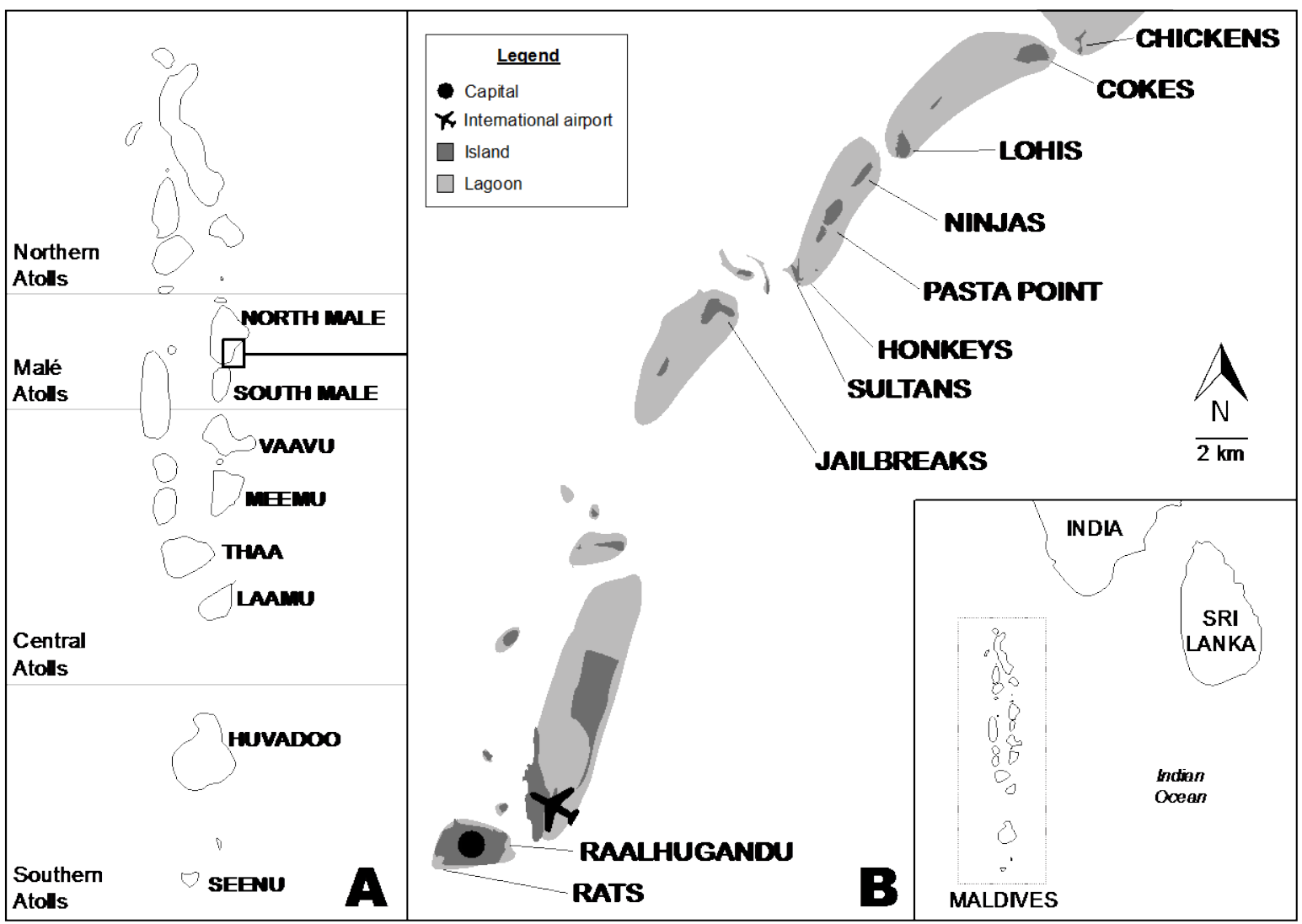

The Southern Atolls are substantially less accessible than the Malé Atolls. It takes several days by boat, or 45 minutes by air, to reach these atolls from the international airport in the capital city of Malé. Currently, surf tours to the Southern Atolls operate at lower volumes, higher luxury, and 60-80\% higher prices than those to the Malé Atolls. Most of the Maldives surf tourism industry operates in North Malé Atoll (NMA) and South Malé Atoll (SMA). There are ten surf breaks in NMA and seven in SMA. Most surf breaks in SMA, but only a few in NMA, are controlled exclusively by individual island resorts. The most active conflict and contest occurs in NMA, where there is easiest access (1-2 hr. by boat from Malé), greatest demand, highest surfer numbers, greatest diversity in land tenure, and greatest uncertainty over access rights. This analysis focuses on the disputed surf breaks of NMA (Figure 1B).

The surf breaks of NMA are all reef breaks, where the waves break sharply on the abrupt edge of a coral reef, at an angle to incident swell. This contrasts with beach breaks on sandy beaches, where the waves break over gradually shelving sand bars. Reef breaks typically form consistent high-quality waves, but they require high skill to avoid wipe-outs onto shallow coral rock, and they have a narrow take-off zone which limits the number of surfers who can surf safely at the same time. The NMA breaks are more forgiving than many reef breaks, such as those in Indonesia, because the outer edges of some NMA reefs are covered 
by shelving benches of broken coral fragments which soften the surf break, especially at higher tide levels. This is one of its attractions in the international surf tourism market: highquality reef-break waves, but with lower risk of injury for older surfers. Even so, however, the recreational capacity (Buckley, 2002b, 2015) of the NMA surf breaks is very restricted (Buckley, Guitart, \& Shakeela, 2014).

The 10 surf breaks in NMA are listed in Table 1, together with current accessibility, and official land use (inhabited or uninhabited) in the adjacent islands. Of these 10 surf breaks, two (Rats, Raalhugandu) are on the capital-city island of Malé and are used largely by local surfers. Two (Pasta Point, Lohis) are adjacent to island resorts which market specifically to surf tourists, claim exclusive access rights, and actively block access by any boat-based surfers. One (Ninjas) is adjacent to an island resort which does not cater specifically to surfers, and which allows access to boat-based surfers (Club Med, 2015). One (Jailbreaks) is adjacent to a government-owned island (Himmanfushi) with some local inhabitants, used as a prison. It is currently open-access and used by boat-based surfers.

Table 1. Surf breaks, access, and island land tenure, North Malé Atoll

\begin{tabular}{lllll}
\hline $\begin{array}{l}\text { Surf } \\
\text { Break }\end{array}$ & $\begin{array}{l}\text { Access in } \\
\text { mid 2016 }\end{array}$ & $\begin{array}{l}\text { Potential } \\
\text { Access }\end{array}$ & Island & $\begin{array}{l}\text { Land } \\
\text { Use }\end{array}$ \\
\hline Raalhugandu & $\mathrm{C}$ & $\mathrm{O}$ & Malé & $\mathrm{I}$ \\
Rats & $\mathrm{O}$ & $\mathrm{O}$ & Malé & $\mathrm{I}$ \\
Jailbreaks & $\mathrm{O}$ & $\mathrm{O}$ & Himmafushi & $\mathrm{I}$ \\
Honkeys & $\mathrm{O}$ & $\mathrm{P}$ & Thanburudhoo & $\mathrm{U}$ \\
Sultans & $\mathrm{O}$ & $\mathrm{P}$ & Thanburudhoo & $\mathrm{U}$ \\
Pasta Point & $\mathrm{P}$ & $\mathrm{P}$ & Chaaya & $\mathrm{U}$ \\
Ninjas & $\mathrm{O}$ & $\mathrm{P}$ & Huraa & $\mathrm{U}$ \\
Lohis & $\mathrm{P}$ & $\mathrm{P}$ & Hudhuranfushi & $\mathrm{U}$ \\
Cokes & $\mathrm{O}$ & $\mathrm{O}$ & Thulusdhoo & $\mathrm{I}$ \\
Chickens & $\mathrm{O}$ & $\mathrm{P}$ & Kuda Villingilli & $\mathrm{U}$ \\
\hline
\end{tabular}

$\mathrm{C}=$ Closed, $\mathrm{O}=$ Open, $\mathrm{P}=$ Private, $\mathrm{I}=$ Inhabited, $\mathrm{U}=$ Uninhabited

Two surf breaks (Sultans and Honkys) are adjacent to an uninhabited island (Thanbhurudhoo) controlled by the Maldives military. These two breaks are highly iconic, and are used heavily by boat-based surfers, both locals and tourists. They are also readily accessible from the island resort that controls the break at Pasta Point, so surf tourists staying at that island frequently also surf at Sultans and Honkys. There have been development proposals for an exclusive-access resort on this island, considered in more detail below.

One surf break (Cokes) is adjacent to a now inhabited island (Thulusdhoo) which was formerly leased, as an uninhabited island, for light industry including a fish cannery and a beverage bottling plant. This island is now subdivided into small residential plots and small enterprises, including low-key restaurants, souvenir shops and guesthouses. Some of these guesthouses cater specifically to low-budget surf tourists travelling independently (Rifaey, 2012), and at least one of these advertises internationally (Cokes Surf Camp Maldives, 2016). The most northerly break, Chickens, is adjacent to an island that is classified as uninhabited, but supports a small number of low-key residential premises. There have been suggestions for resort or guesthouse development on that island, but no formal development proposals. 


\subsubsection{Principal Stakeholders}

There are seven stakeholder groups, with different interests, namely: island-resort owners and staff (foreign or Maldivian); resort-based surfing tourists; live-aboard charter-boat owners and staff (foreign or Maldivian); boat-based surfing tourists; local Maldivian-owned surfrelated enterprises; independent travelling surfers using those enterprises; and local Maldivian resident surfers. Some individuals belong to multiple stakeholder groups. For example, either locals or foreigners may own both boats and resorts, and locals may work for surf businesses but also surf recreationally themselves. These stakeholder groups, and the individuals involved, compete for access and control over surf breaks.

Most of the Maldives tourism industry operates in North Male Atoll (NMA), close to the international airport. Smaller airstrips have been built in the Central, Southern and other Atolls; but the costs of transport between atolls render these Outer Atolls more expensive destinations. Tourism leases run for 50 years initially, with 49-year extensions available for US\$5 million (Shakeela, Becken, \& Johnston, 2014). The principal focus of the island based tourism industry is unspecialised mass-market beach tourism, aimed at sun-seeking northern Europeans during winter (Anon, 2015). A large secondary market is in honeymoon tourism. Some island resorts, but not all, also offer island-based diving or surfing (Buckley et al., 2014). Most of the resorts that offer surfing options claim exclusive access to adjacent surf breaks. These resorts are expensive, and their surfing clients pay for exclusivity as well as luxury.

There is a growing boat-based sector, including luxury cruises and specialized live-aboard charter boats, departing directly from a dock at the international airport (MTAC, 2015). Most of these vessels operate dive tours from August to April, and surf tours from May to October. In 2014, there were 161 vessels registered for tourism in the Maldives and offering surf and/or dive tourism, with a total berth capacity of 2,739 (MoT, 2015b). Live-aboard charters are generally all-inclusive, and the vessels move between dive sites or surf breaks depending on conditions, with no need for land access. Some individual vessels, however, are affiliated with, or co-owned by, a private resort, which may grant their clients additional privileges. These live-aboard boats are also expensive, and their surfing clients pay for the opportunity to surf whichever breaks are working best on any given day, at the best time of day relative to swell, tides and wind. That is, they rely on their captains' knowledge and skill, and the opportunity to anchor near different breaks on different days.

Legislation introduced in 2008 allowed Maldivian citizens to construct guesthouses on inhabited islands, to stimulate local island economies (MTAC, 2012a). This approach allowed less wealthy Maldivians to build tourism-based livelihoods. This made them less dependent on resort employment, and more invested in their own natural resources. The number of locally-owned guesthouses has expanded rapidly (Figure 2), from 24 guesthouses with 400 beds in 2008, to 220 guesthouses with 3,209 beds in 2014 (MoT, 2015b; MTAC, 2013). Most of these are on the island of Malé and are not related to surf tourism specifically. A few, however, are on islands such as Thulusdhoo, and are patronised particularly by independent travelling surfers (Rifaey, 2012). There are also small businesses that offer boat shuttle services between islands, so independent surfers need not always surf the same break. New regulations in August 2016 (Avas, 2016) have restricted guesthouses to islands with 24hr electricity, telephone and internet, medical and police services, and water supply and wastewater treatment connections. This is a significant restriction. 
Figure 2. Growth of registered accommodation establishments.

Data from (MoT, 2015b; MTAC, 2013).

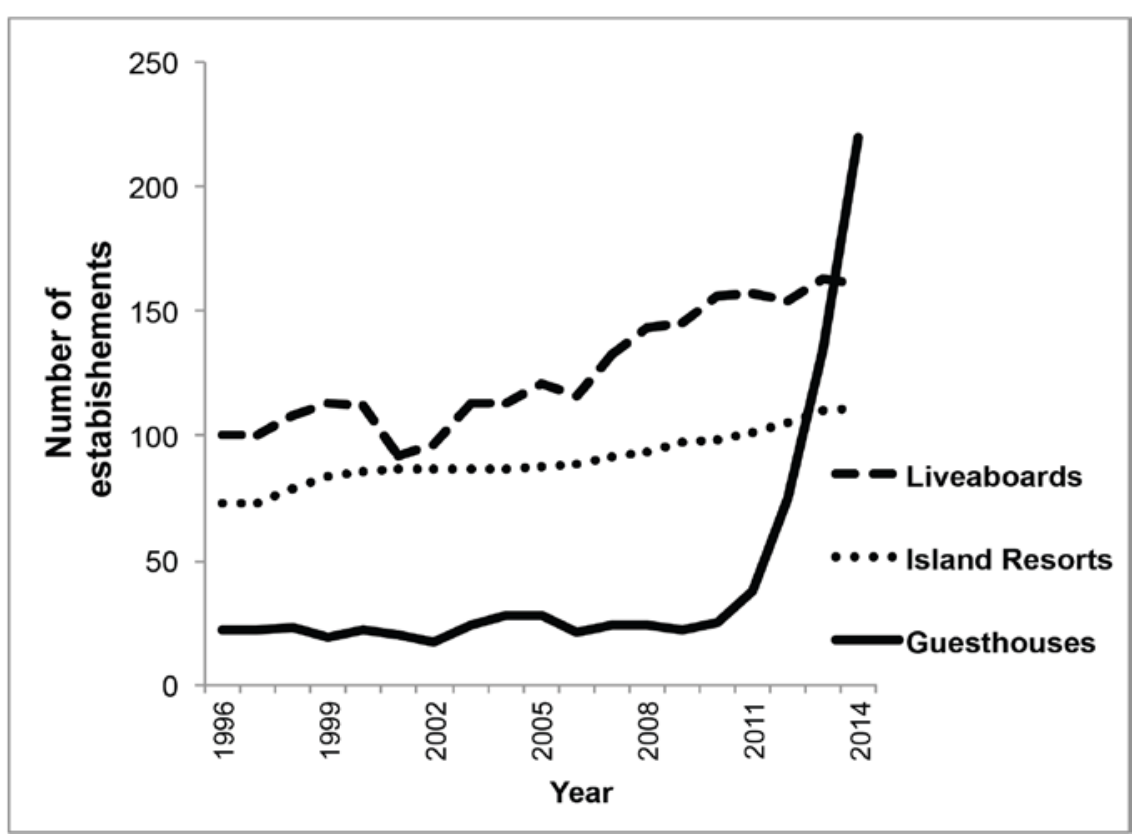

Local surfing has grown greatly over recent decades. The Maldives Surfing Association (MSA) was founded in 2000, and the Maldives Body Boarders Association (MBBA) in 2013. Most local surfers live in Malé or nearby inhabited islands. These surfers use the two Malé surf breaks most commonly, but when opportunity arises they also travel in small boats to the other NMA breaks. They therefore value a right of access to these breaks, for themselves if not universally. Maldivian employees of some of the island resorts and live-aboard surf charter vessels have also become good surfers, and surf either recreationally or professionally. Some work as guides for independent travelling surfers, ferrying them from accommodation in Malé to the various surf breaks in North Male Atoll. Some work as guides or photographers for clients of commercial surfing enterprises, both boats and island resorts.

There was general agreement across stakeholders, interviewees and documentary sources that the Maldives are marketed as an uncrowded surf "nirvana” (Ponting and O’Brien, 2014): "remote, uncrowded spots" (Dante in Nettle 2012), with "warm water, consistent swells and perfect waves" (Maddogmorley in Nettle, 2012). It was also generally agreed that as with many island surf destinations worldwide, the surf breaks of the Maldives have in fact become crowded, so that conflicts are commonplace. These concerns have been examined extensively in surf tourism research (Buckley, 2002a,b; Martin \& Assenov, 2012; Ponting \& O’Brien, 2014), and are not recapitulated here except as context for the more specific issues considered below. Issues such as seasonality, the greater time and expense required to reach the Outer Atolls, the role of the international surf media, the profile of the typical international surf tourist, and the cultural differences between locals and tourists, were also acknowledged by all stakeholders, with little disagreement. These are either purely factual issues, or issues considered in previous research, so they are not reiterated here. 
For a number of other commonly identified themes, however, very different viewpoints were expressed by different stakeholders. These related to land tenure, legislation, development policies and proposals, the perceived rights of each stakeholder group, and the bases for such rights. These issues have not been considered in any detail in any previous research on island surf tourism destinations, and are therefore analysed here.

\subsection{Critical Issues}

\subsubsection{Capacity, Crowding and Conflict}

The Maldives Surfing Association (MSA) has stated that each of the Maldives reef breaks can accommodate a maximum of 15 surfers at any one time (MSA, 2012). Many surfers would consider even that number to be too many, with the best surfing with $<5$ surfers in the water. Several factors have contributed to increased crowding. Island resorts have boosted surf-specific tourism marketing. An increasing number of live-aboard charter boats have turned to surf tourism in the off-season for diving. The number of local surf guides and guesthouses is growing, increasing the number of low-budget independent travelling surfers who can stay for a longer periods of time. As a result, in recent years the NMA breaks became severely overcrowded during peak surf tourism season. Frustration over crowding is shared amongst all surfing stakeholders.

Surf tourists emphasise that surfing is no longer enjoyable when there are too many surfers at the same surf breaks. "It is so crowded out there, we couldn't get waves - this is not fun!" (Interview, surf tourist on live-aboard charter boat [BT1]). "It's really dangerous there! Reef breaks can only hold a number of people, when there's too many, accidents can happen. I am scared every time I go surfing here" (BT2). Surf tourists writing in online blogs express similar sentiments. "I have never, ever seen a line-up with such aggression, ruthlessness and general unpleasantries” (William in Nettle, 2012).

Local surfers and foreign surf guides also mentioned aggression resulting from crowding. In one recent incident (Maldives Finest, 2015), a local Maldivian surf guide politely asked some unguided independent international surf tourists to follow accepted surf etiquette, and instead the tourists attacked him violently. "With increasing number of surf tourists, surf breaks are becoming war zones... The joy of riding waves has gone" (Local surfer [LS1]). "Everyday surf breaks are becoming war zones" (Rifaey, 2012b). "I see lots of fights in the water at these [open access] breaks... I don't like to bring our tourists here... there's always problems, lots of fights and we have to leave" (Foreign surf guide working at private resort [FG1]).

\subsubsection{Privatization and Exclusivity}

Two new pieces of legislation were developed in 2012, providing island resorts with a greater degree of legal control over access to adjacent surf breaks. The first of these was a lagoon zoning regulation, which restricted boat access to marine areas adjacent to the resorts (MTAC, 2012b). These restrictions included live-aboard charter boats, as well as local boats used for fishing and transport. This regulation is still in force. The second was a resort boundary regulation, which gave island lessees the right to control all access within $700 \mathrm{~m}$ of their leased island (MTAC, 2012c). That regulation was subsequently rescinded in 2014, but 
incompletely, leading to further confusion and conflict (MoT, 2014). It was then reinstated in 2015 (MoT, 2015a).

Two of the three resort-based tourism operators in NMA used this legislation to introduce exclusive controls over the adjacent surf breaks. These controls are official described, somewhat euphemistically, as surf management plans. The resorts actively drive other surfers away from the surf breaks to which they lay claim, even using the Maldives police to arrest people. They cite crowding and aggression in justification: "a response to overcrowding of the resort's house wave ... surfer numbers have spiraled out of control ... aggression in the water ... nobody wants that on their holiday...” (Levings in Saunders, 2013).

Chaaya Island Dhonveli Resort, which lays claim to the adjacent break of Pasta Point, nominally allows a maximum of 30 surfers to stay at any one time (Atoll Travel, 2015). Hudhuranfushi Surf Resort, which lays claim to the adjacent surf break known as Lohis, allows a maximum of 45 (World Surfaris, 2015). Surfers not staying at Hudhuranfushi may surf at Lohis only by buying a daily surf pass at a cost of US\$175, subject to availability (FG2). Both of these resorts also cater to non-surfing tourists (Buckley et al., 2014). It is not clear how well these limits on surf tourist numbers are implemented in practice. In addition, since these numbers are well above the effective capacity of each resort's local wave, surfers at each resort must either stagger their use of the resort wave, or ask the resort to shuttle them to other, open-access waves, adding to crowding at those waves. This also happens when surf tourists, or resort surf guides, think that surfing conditions will be better at other surf breaks.

Foreign surf guides and commercial photographers working at these resorts generally support this access control, because it improves satisfaction for the resorts' surfing clients, and hence boosts business by maintaining premium prices. "The surfer management plan at Hudhuranfushi Resort is an awesome idea... guests can surf one of the best waves in the Maldives without crowds" (Kotch in Saunders, 2013). This view is not surprising: from a commercial surf photographer's perspective, a resort-only surf break means that all photographs are of resort guests, not independent surfers; and since the resort guests are generally more wealthy, they are more likely to pay to purchase professional photographs.

Individual surf tourists staying at these resorts also support exclusive access, since in their view, this is what they are paying for. "I am willing and happy to pay for access to waves with managed crowds" (Surf tourists from resort [RT1]). Similar views are expressed by some online commentators: “I'm all for privatization of breaks. You travel half way around the world, use your two week vacation and drop $\$ 4.5 \mathrm{~K}$ on a surf trip and end up paddling out to a dream break with 30-40 others hassling for a wave. It's way too crowded out there... This will allow those willing to pay to get what they actually paid for...” (Bill555 in Mull, 2013).

In general, owners of live-aboard surf charter vessels are not in favour of privatization of the island resort waves, since it limits the surfing options for their own clients. Some of the boats, however, are co-owned or otherwise associated with particular resorts, and have negotiated special privileges. The voice of the boat owners is therefore less coherent, and more muted, than might otherwise be expected. Their clients, however, are definitive in their opposition to access control at resort-island surf breaks. "We were surfing super crowded Jails... we look over to Pasta Point, it's perfect and uncrowded. So unfair! We paid so much money to get here ... and now we're told we can't surf in peace. Not happy!” (BT3). 


\subsubsection{Rights and Equity}

Some of the arguments over privatization are purely economic, but some are essentially ethical or philosophical. The latter fall into four main categories. The first of these views is that all waves everywhere should be open-access since this is part of the core code of surfing. That is, it is an activity-based philosophy. "It is inherently wrong to privatize surf." (Nikitin in Connolly, 2012). "No-one should be able to own a wave." (Jacobson in Connolly, 2012).

"Waves cannot be owned or bought." (Infamous Hambe, in zigzag, 2016) "Waves should not be owned, and should be accessible to all locals and visitors." (Nettle, 2012). "Anyone associated with ... exclusive rights to waves ... is not a true surfer." (LiquidDestination, in Nettle, 2012). "We want the waves... to be free for all." (Nettle, 2012). "How can you close the ocean?" Curren, quoted in Howard, 2012).

The second view is that whilst some waves may be privatized, waves that have historically been open-access should continue to be considered common property. "Established and popular breaks should be considered public domain" (Bjorklund in Conolly, 2012). "They [resort operators] should not be able to take over public assets for their private use" (Lemmings, in Conolly, 2012).

The third argument is one of social justice, that access to waves should not be determined by wealth. "Welcome to the future. The best waves reserved for the rich!" says one online commentator ironically (Blindboy in Nettle, 2012). "So only the rich have access?" asks another (Carpetman in Nettle, 2012). "No one should ever have to pay anyone to ride a wave” claims a third (Carson in Mull, 2013). "Doesn't the entire premise of wave ownership go against surfing's 'Aloha spirit'?” (Heisey, 2013). All these are international arguments.

The fourth argument is more localised: all waves within the Maldives should belong to all citizens of the Maldives, so local surfers should not be excluded. "No native of any country should be restricted from surfing their very own surf breaks" (Save Thanbhurudhoo, 2015). "All the waves in this country should be free for all local waveriders to surf." (Rifaey, 2012). "We didn't even realise how valuable the freedom to surf these waves was, because we never thought that it'd be taken away from us. The waves were always there and it was free to surf." (Rifaey, 2012b). "These are our islands, our home, our surf breaks; shouldn't we be able to surf here?” (LS5). "It is our birthright, the right to surf our waves!” (LS4).

\subsubsection{Economics}

At local scale and short term, resort owners and resort-based surf guides want exclusive control of adjacent waves, to maximise their own income. Their clients agree, since that maximises their reward from purchasing an island-based surf tourism package. Boat owners, or at least those without privileged access to surf breaks claimed by resorts, argue for open access to all waves, since that maximises their income. Their clients agree, since that maximises their reward from purchasing a boat-based surf tourism package. Owners of local guesthouses that cater to independent surf tourists, would prefer that each island should have the right to control access to adjacent breaks, since that would improve their income substantially. Such rights are not currently implemented for non-resort islands.

There are, however, a number of complexities recognised by some or all of the stakeholders. For example, owners of local guesthouses may have commercial or family ties to owners of 
souvenir shops or restaurants on the same islands, which may gain most of their revenue from boat based tourists (Rifaey, 2012). "Surf tourism is putting food on the table for a lot of these families." (Rifaey, 2012). "There are a number of locals who depend on these clients for their paychecks, such as the surf guides, the captain and crew who work on the boats, and the people in the offices that operate these safaris." (Rifaey, 2012).

More broadly, many stakeholders recognise that either crowding (through open access to breaks), or restricted access to surf breaks (through privatization of some breaks) could damage the international reputation of the Maldives as a surf tourism destination which is in competition with other such destinations worldwide. Indeed, this could spill over to other sectors of the Maldives inbound tourism industry, with much broader economic consequences.

"People will look elsewhere ... for their surf holiday... surf breaks don't all work at the same time ... narrow the options and the whole destination becomes less appealing" (Burgo in Nettle, 2012). "The trip we've been planning to the Maldives, at considerable expense, will not produce the uncrowded, great waves we anticipated. So we'll look elsewhere." (Dante in Nettle 2012). "Privatising ..Sultans will smash the surf tourism industry in North Male for all involved." (Burgo in Nettle 2012). "In the future, this could be very bad for business...when surf tourism goes down..." (Aznil in ABC News, 2013). "Maldives should be a shining light and known as one of the best places in the world to take a surf trip... [but with] private waves only accessible to wealthy resort guests, the reputation of the Maldives is on the decline." (Informant 6 in Save Thanburudhoo, 2013).

\subsection{Stakeholder Narratives \& Trigger Events}

\subsubsection{Stakeholder Narratives}

The relative scale, interests, and justifications or "narratives" of each of the seven principal surf stakeholder groups are summarised in Table 2. There are additional stakeholders whose views affect outcomes for surf stakeholders, but which are not considered here. These include: elected government representatives at national, atoll and island level; heads of government agencies or portfolios with responsibilities such as tourism, infrastructure or defence; and foreign and local owners and investors in industries such as engineering, construction, architecture and marketing.

The principal point of disagreement between the seven surf stakeholder groups, is whether or not individual surf breaks should be privatized. Broadly, foreign owners of luxury island resort businesses, and wealthier surfing tourists staying at those resorts, support privatization of individual surf breaks, with exclusive control of access; local surfers, local business owners, low-budget independent travelling surfers, live-aboard boat charter operators, and boat-based surfing tourists oppose it. Their exact positions differ (Table 2), depending on the details of proposed access rights. Political advocacy by each stakeholder group reflects its own interests, but the justifications provided differ even between groups with the same advocacy positions. 
Table 2. Surf stakeholder interests and narratives in surf break access.

\begin{tabular}{|l|l|l|l|l|l|}
\hline Stakeholder & & & & & Narrative \\
\hline & $\begin{array}{l}\text { open } \\
\text { to all }\end{array}$ & $\begin{array}{l}\text { open to } \\
\text { locals }\end{array}$ & $\begin{array}{l}\text { island } \\
\text { guests } \\
\text { only }\end{array}$ & $\begin{array}{l}\text { resort } \\
\text { guests } \\
\text { only }\end{array}$ & \\
\hline & & & & & \\
\hline Island resorts & & & & $*$ & guest safety \\
\hline Resort surfers & & & & $*$ & paid for right \\
\hline Live-aboards & $*$ & & & & tourism growth \\
\hline Boat surfers & $*$ & & & & paid to surf \\
\hline Guesthouses & & & $*$ & & local business \\
\hline Free surfers & $*$ & & & & surfing code \\
\hline Local surfers & & $*$ & & & our birthright \\
\hline
\end{tabular}

Thus, island resorts and island based surf tourists both stand to gain from privatization, but the arguments advanced by the former are tied to safety and crowd control, whereas those advanced by the latter are simply that this is what they paid for, and without exclusive access, they will take their surfing holidays elsewhere. Live-aboard boat owners need access to breaks for their clients, but they are muted in their opposition to island resorts because of cross-ownership, special privileges for some boat owners, the dual-season dive-surf industry, and political connections and considerations. Their clients, however, are emphatic that they paid to surf in the Maldives, and once again, if they are restricted as to which breaks they can access, they will simply go elsewhere. Therefore, the boat owners present a political advocacy position centered around overall tourism revenue to the country. That is, they express concern that privatization of surf breaks will detract from the nation's overall ranking as a surf tourism destination, and that this may have flow-on effects to other sectors. For example, if boats cannot attract surfing clients and therefore go out of business, that would affect the much larger and more lucrative dive tourism business.

Local surf businesses, independent travelling surfers, and local surfers are generally opposed to privatization, but there are caveats. For example, some local surfers work at island resorts, so they benefit from privatization. Some don't care about open access for tourists, only about open access for locals. Their advocacy is largely centered around the idea of a Maldivian birthright to surf breaks, even though local surfing is relatively new. Guesthouse owners would like to gain control over surf breaks adjacent to the islands concerned, since then they would profit either by charging live-aboard boats to bring their clients there, or by charging higher prices to independent travelling surfers staying in their accommodation. Their advocacy is centered around promotion of local entrepreneurial opportunities. Independent travelling surfers are generally against privatization, but they might change their minds if they could gain preferential access to particular surf breaks by staying in local guesthouses. At present, their advocacy is based on the idea that there is a universal code of surfing, which requires that all waves should be free. In fact, however, this code evolved in Hawai'i and Western nations, and does not necessarily have any basis in Pacific or Indian Ocean island nations with traditional tenure over fishing reefs.

The development of political advocacy regarding surf break access and privatization has been driven recently by two key controversies, which may be considered as trigger events. These are outlined briefly below, followed by consideration of their consequences. 


\subsubsection{Thanbhurudhoo Trigger Event}

The single most critical dispute over access to surf breaks in the Maldives has been a proposal by a foreign-owned development corporation to build a surf resort on the island of Thanbhurudhoo, including exclusive access to the iconic breaks of Sultans and Honkys, which are currently open access. This proposal sparked intense debate both locally and internationally, and mobilised stakeholder groups both pro- and anti-privatization more generally (Buckley, et al., 2014).

Thanburudhoo Island (also spelt Thamburudhoo) is managed by Sifainge Welfare Company (SIFCO), which is a branch of the Maldives National Defence Force (MNDF). In 2012, it was leased to a foreign development company, Singapore-based Telos Investments, for the construction of a boutique surf resort with exclusive control over the two adjacent breaks (Conolly, 2012; MSA, 2012; Mull, 2012).

This proposal triggered protests against privatization of surf breaks, from both local and international surfing communities. Local surfers, with international support, initiated a campaign called 'Save Thanburudhoo', aimed at halting this specific development (Save Thanburudhoo, 2012) and more broadly, abolishing all surf exclusivity policies in the Maldives. Signatures were collected online for a petition to present to the Ministry of Tourism, Arts and Culture.

These local views were expressed as follows. "Thanburudhoo has been shared by many people for ages, and they decide to give it away without consulting... locals have been going there every day... and one day when we go there they are like no you can't come here, it is owned by a foreign person, you need to have a license. I think it's stupid." (Save Thanburudhoo, 2013). "It is the only island in the atoll that is freely accessible to both locals and foreigners." (Rifaey, 2012). "It's not worth to just give it to one person for his own interest... Lots of safari boats and locals have been utilizing and making money on it. Money has been distributed among locals, safari owners, and the crew, it's been going all over the country." (Informant 2 in Save Thanburudhoo, 2013). "We feel like we have no voice. And that's part of the problem." (LS5).

Economic issues were also raised repeatedly. "Surf tourism is growing fast ... and the majority of surfers come to North Male atoll to surf, since it has some of the best and most consistent waves in the country. If Thamburudhoo is a resort, surf tourism in this atoll will not be sustainable. The only accessible surf breaks (Thulusdhoo and Himmafushi) cannot hold all the surfers from their surf camps, their local surfers, the tourist resorts, the safari boats and the local surfers from other islands.” (Rifaey, 2012).

In 2013, three Australians who had worked as surf guides in NMA, filmed a documentary to raise awareness about the issues associated with privatization of surf breaks. They interviewed members of the Maldives Surfing Association, the Maldives Diving Association, local surfers, and government officials. During filming, they were arrested by the Malé police, who supposedly had suspicions of a protest against government plans to lease Thanburudhoo and privatize the breaks (ABC News, 2013). They were released after being held by police for one day (Pierson, 2016). 
These events produced some political effect. In early 2014, the resort boundary regulation was amended excluding all 'popular' surf breaks and dive sites (MoT, 2014). However, this amendment was vague, stating that the Ministry must publish a list of popular sites and define management plans before the regulation came into effect. This created confusion and further rivalry among surf tourism operators. Live-aboard surf charter boats began promoting their tours with new access to all waves, whereas island resorts continued to prosecute surfers whom they viewed as trespassers (Hameed, 2014; LUEX, 2014; Nettle, 2014; Surf Atoll, 2014; Temperley, 2014). The boundary regulation was amended once again in early 2015, granting private boundaries of 700 meters to all resorts (MoT, 2015a).

In 2013, the Thanbhurudhoo resort developers stated on their website that they would start operating in 2017, at which time access would be strictly regulated (Thanburudhoo Resort, 2013). In January 2015, Telos signed an operating agreement with Singapore-based Patina Hotels \& Resorts. In August 2015, however, the Maldives Government annulled the resort lease, announcing that the island would be kept as a surfing heritage site for all locals and foreigners to enjoy (Jameel, 2015; Surfer Today, 2015). This was perceived as a victory by local surfers, locally owned surf tourism businesses, and live-aboard charter businesses in the Maldives, helped by the interest of at least some international surfers. It gave them a new sense that they possessed political power, which could be used to counteract that of wealthy foreign and Maldivian owners of island resorts.

\subsubsection{Raalhugandu Trigger Event}

In the capital city island of Malé there are two surf breaks, Raalhugandu and Rats, which are popular particularly for local Maldivian surfers who live nearby. International surf tourists generally do not frequent these waves. The majority of surfers from Malé learned to surf at Raalhugandu. This break has been closed by the Maldives Government, to allow construction of a public road bridge linking Malé to the neighbouring (airport) island of Hulumale. Named the "Maldives-Chinese Friendship Bridge", it is being constructed by Chinese contractors as part of a USD 210 million project funded by the Chinese Government (Anon, 2016). Bridge construction begun in 2016, and government authorities closed access to the Raalhugandu break until the bridge is finished, purportedly owing to concerns over safety.

Local surfer associations have protested against this closure, arguing that many locals surf there daily, and that this brings local economic benefits (Pierson, 2016). They have also argued that whilst there is apparently a formal environmental impact assessment for bridge construction (CDE Consulting, 2016), (a) it is written in Chinese; (b) it is not publicly available; and (c) it does not adequately consider the impacts of the bridge on surf quality (Naafiz, 2016; Riptide, 2016a). "Representatives from the MSA tried to obtain the document, but were told by the Maldives Government that it was only available in Chinese." (Anon, 2016). Local surfers have formed a specific organization against the bridge development, named 'Save Our Waves' (Sattar, 2016).

The views of local surfers are strongly held. They argue that Raalhugandu may become unsurfable through side effects of the construction process (Sattar, 2016). "The surfers of Varnulaa Raalhugandu are protesting because the government authorities are not listening to us. We are scared, hurt and angry. Raalhugandu is the only place of happiness that a lot of surfers have in this crowded, unhappy city" (Sattar, 2016). Many local surfers have continued to surf there in protest, and some, including the president of MSA, have been arrested 
(Riptide, 2016b). These surfers also point out that the surf tourism industry in the Maldives employs local Maldivian surfers, and that those industry employees learned their surf skills at Raalhugandu. If this break is no longer accessible, the next generation will have no local employees. "If Raalhugandu is lost, it will create a domino effect for surfing and surf tourism in the Maldives." (Castle, 2016).

\subsubsection{Exogenous to Endogenous Control}

As a result of these conflicts over access to surf breaks, local stakeholders have gradually recognised, assumed and developed their own political power, which did not previously exist. That is, there has been a gradual transfer from exogenous to endogenous control of access. Until about 2008, control was largely held by wealthy investors, foreign as well as Maldivian. These investors had the capital, management and marketing expertise, and possibly highlevel political connections, to gain preferential access to island leases, and build and operate resorts and charter vessels.

After that date, and especially after the Thanbhurudhoo trigger event in 2012-2015, local interests realised that they had the political power to oppose any further privatization, at least by foreign corporations. After the Raalhugandu trigger event they realised that this power was insufficient to oppose major Maldivian government agencies. Even so, however, it seems likely that the future of access to surf breaks in the Maldives will be driven far more by endogenous debate over net benefits to local stakeholders in the Maldivian surf sector, and to the Maldivian economy as a whole, and less by external interests seeking to capitalise on surf resources over which they can gain control.

From an analytical perspective, we can recognise this shift from exogenous to endogenous control as a second-tier axial theme, a powerful and large-scale mechanism that reflects and underlies the first-tier axial coding revealed through differential stakeholder narratives. Comparing the Maldives to other island surf tourism destinations such as the Andaman Islands, Papua New Guinea (O’Brien \& Ponting, 2013), and the offshore islands near Sumatra, Indonesia (Buckley, 2002a,b), we can see that similar shifts in control have occurred or are occurring, with different destination countries at different stages.

Similar transfers of political power have also occurred in other subsectors of nature, eco and adventure tourism. For example, there are now locally-owned as well as foreign-owned trekking, rafting, climbing, and mountaineering businesses in the mountain ranges of the Andes and Himalayas, and the tropical peaks of Africa and South-east Asia. There are also locally-owned as well as foreign-owned wildlife-watching tours and lodges in the safari destinations of Africa, Asia and Latin America. Similar changes may also occur in other industry sectors, and models developed in tourism may thus be applicable more broadly. The social, economic, political and legal processes by which these transfers occur, and the consequences of these changes, thus merit research attention at much broader scale.

\section{CONCLUSIONS}

Access to surf breaks in the Maldives does indeed illustrate well that contest over control of newly valuable natural resources operates via political rather than purely administrative processes. Initially, tourism in the Maldives used an exogenously driven enclave model, with 
maximum separation between tourists and locals. Subsequently, local involvement increased through three steps. First, locals became been involved in the commercial surf tourism industry, generally as resort staff. Second, the opportunity to establish local guesthouses created greater interest in control of surf resources. Third, an increasing number of Maldivian citizens are now surfers themselves. This reflects the transfer of tacit knowledge from international visitors to local residents (Buckley \& Ollenburg, 2013). The transfer from exogenous to endogenous control in this practical case study contrasts with theoretical predictions (Abatayo \& Lynham, 2016).

Patterns and processes for surf tourism in the Republic of Maldives have parallels in other surf tourism destinations and other adventure tourism activities, but are not necessarily reflected directly. In the Maldives, for example, commercial surf tourism originated as an offshoot of enclave island tourism, and boat-based surf tourism followed later, as an offshoot from the boat-based dive tourism industry. In the Mentawai Islands of Sumatra, Indonesia, in contrast, boat-based surf tourism led the development of the sector, with island surf resorts and then island multi-activity resorts following subsequently (Buckley, 2010). In Fiji, an iconic surf break at Tavarua was long controlled by a local resort that capped surfer numbers, through a locally negotiated agreement with the nearby residents. In 2010 this agreement was overridden at national level, leading to crowding and dissatisfaction. In Papua New Guinea, a local surfing associations has gained exclusive control over adjacent surf breaks (O'Brien \& Ponting, 2013), though it is always possible that future political processes may override this.

Our focus here was on conflicts between surf stakeholders, over access to surfing sites. As indicated in interviews and popular surfing literature, however, these are closely bound up with crowding-related conflicts between individual surfers, which have been subject to quite substantial research effort. Phenomena such as surf rage (Buckley, 2015; Mixon, 2014; Usher \& Kerstetter, 2015), surf localism (Mixon, 2014; Usher, Goff, \& Gómez, 2016; Usher \& Kerstetter, 2015), and surf tribalism (Anderson, 2016; Goulding, Shankar, \& Canniford, 2013) have all been examined either independently, or in conjunction with the actual or potential protection or privatization of surfing sites (Nelsen, Cummins, \& Tagholm, 2013; O’Brien \& Ponting, 2013; Ponting \& O’Brien, 2014). Our results here show how those localscale interpersonal conflicts are embedded in broader scale stakeholder conflicts over property rights.

None of those previous studies included a systematic analysis of the evolution of rights and political positions for different surf stakeholders, with regard to access to surfing sites. In particular, none identified the gradual transition from exogenous to endogenous control described here. This transition contrasts with the more commonplace change, from local customary to national government control over property rights, both in tourism and other industry sectors (Abatayo \& Lynham, 2016). It is analogous to the devolution of control from modern national governments to first-nations traditional landholders, under land rights frameworks. It thus yields an interesting contribution to the theoretical frameworks of property rights in general.

In the Maldives specifically, it remains to be seen whether it proves to be merely a temporary and small-scale reversal of centralised control over natural resources, or the forerunner to larger-scale changes. For the surf tourism industry, it provides a case study and counterpoint to analogous, but different, patterns of change in other iconic surf nations (Buckley, 2002a,b; Martin \& Assenov, 2012; O’Brien \& Ponting, 2013; Ponting \& O’Brien, 2014). 
The analysis of political processes and stakeholder perspectives in the control of newly valuable natural resources, illustrated here for a particular region and subsector in adventure tourism, thus adds a new dimension to the study of both tourism and property rights. There are many opportunities to apply similar approaches in other places and subsectors. A wider set of case studies would provide confidence in the breadth of these findings, and applications in tourism and natural resource management more generally. 


\section{REFERENCES}

Abatayo, A. L., \& Lynham, J. (2016). Endogenous vs. exogenous regulations in the commons. Journal of Environmental Economics and Management, 76, 51-66.

ABC News. (2013). Fears Maldives resort will block surf access. 3 September 4:07 mins. Retrieved 20 January 2015, from Australian Broadcast Corporation, http://www.abc.net.au/news/2013-09-03/an3a-campaign-to-block-maldvian-resort-monopolyon-surf/4932154

Adams, W. M., Brockington, D., Dyson, J., \& Vira, B. (2003). Managing tragedies: Understanding conflict over common pool resources. Science, 302, 1915-1916.

Ahn, T. K., Balafoutas, L., Batsaikhan, M., Campos-Ortiz, F., Putterman, L., \& Sutter, M. (2016). Securing property rights: A dilemma experiment in Austria, Mexico, Mongolia, South Korea and the United States. Journal of Public Economics, 143, 115-124.

Anderson, J. (2016). On trend and on the wave: carving cultural identity through active surf dress. Annals of Leisure Research, 19, 212-234.

Anon (2015). Maldives wins the title of 'The World's Leading Beach Destination' at the World Travel Awards 2015. http://maldives.net.mv/13981/maldives-wins-the-title-of-theworlds-leading-beach-destination-at-the-world-travel-awards-2015/

Anon (2016a). Road to ruin: more Maldives wave controversy. http://www.luex.com/magazine/2016/04/21/maldives-raalhugandu-waves-threatened-bridge/ Accessed 4 Aug 2016.

Assaf, A. G., Josiassen, A., \& Agbola, F. W. (2015). Attracting international hotels: Locational factors that matter most. Tourism Management, 47, 329-340.

Atoll Travel. (2015). Cinnamon Dhonveli Maldives. Retrieved 27 November 2015, from Atoll Travel, http://www.atolltravel.com/destinations/maldives/chaaya-island-dhonveli/

Avas (2016, 11 August 2016). Guesthouse Hotaa Hingeynee 24 Gadi Iru Currentaa Fulus Marukazu Hurinama: Qawaidh. Avas. Retrieved 17 August 2016 from https://avas.mv/21188

Ball, S. (2015). The green room: a surfing-conscious approach to coastal and marine management. UCLA Journal of Environmental Law and Policy, 33, 366-404.

Ballet, J., Bazin, D., Koffi, K. J. M., \& Komena, K. B. (2015). Cultural heterogeneity, inequalities, power, and the management of natural resources: how the capability approach contributes to the debate. Society \& Natural Resources, 28, 377-387.

Balli, F., Balli, H. O., \& Louis, R. J. (2016). The impacts of immigrants and institutions on bilateral tourism flows. Tourism Management, 52, 221-229.

Baxter, J. (2010). Case studies in qualitative research. In I. Hay (Ed.), Qualitative research methods in human geography (3rd ed., pp. 81-97). South Melbourne: Oxford University Press. 
Beaumont, E. \& Brown, D. (2016). 'It's not something I'm proud of but it's ... just how I feel': local surfer perspectives of localism. Leisure Studies, 35, 278-295.

Buckley, R.C. (1994). Resource security and environmental property rights: steal, beg, borrow, buy or hire? Environmental Planning \& Law Journal, 11, 175-178.

Buckley, R.C. (2002a). Surf tourism and sustainable development in Indo-Pacific Islands. I. The industry and the islands. Journal of Sustainable Tourism, 10, 405-424.

Buckley, R.C. (2002b). Surf tourism and sustainable development in Indo-Pacific Islands. II Recreational capacity management and case study. Journal of Sustainable Tourism, 10, 425442.

Buckley, R.C. (2003a). Adventure tourism and the clothing, fashion and entertainment industries. Journal of Ecotourism, 2, 126-134.

Buckley, R.C. (2003b). Case Studies in Ecotourism. CABI, Wallingford.

Buckley, R.C. (2010). Adventure Tourism Management. Elsevier, Oxford.

Buckley, R.C. (2015a). Tourism capacity concepts. In T. V. Singh (Ed.), Challenges in tourism research (pp. 268-273). Bristol: Channel View Publications.

Buckley, R. C. (2015b). Adventure thrills are addictive. Frontiers in Psychology, 6, 1915.

Buckley, R.C., \& Ollenburg, C. (2013). Tacit knowledge transfer: Cross-cultural adventure. Annals of Tourism Research, 40, 419-422.

Buckley, R.C., Shakeela, A., \& Guitart, D. (2014). Adventure tourism and local livelihoods. Annals of Tourism Research, 48, 269-272.

Castle, D. (2016). Paradise lost in the Maldives.

https://riptidemag.com.au/2016/03/08/paradise-lost-in-the-maldives/ Accessed 4 Aug 2016.

CDE Consulting (2016). Second addendum to the environment impact assessment for the proposed Hulhule'-Male' bridge project. Prepared for Ministry of Housing and Infrastructure, Male.

Club Med. (2015). Soaking up every minute. Retrieved 3 November 2015, from Club Med, http://www.clubmed.com.au/cm/home.do?LANG=AE\&PAYS=14

Cokes Surf Camp Maldives (2016). Cokes Surf Camp. www.cokessurfcampmaldives.com/cokes-surf-camp/ Accessed 10 August 2016.

Colvin, R. M., Witt, B. G., \& Lacey, J. (2015). The social identity approach to understanding socio-political conflict in environment and natural resource management. Global Environmental Change, 34, 237-246. 
Conde Nast Traveller (2015). The best hotels in the Middle East, Africa \& the Indian Ocean. Retrieved 3 November 2015, from Conde Nast Traveller, http://www.cntraveller.com/awards/readers-travel-awards/2015/best-hotels-middle-eastafrica-indian-ocean

Conolly, D. (2012). Controversy in the Maldives. Retrieved 12 June 2015, from Surfline, http://www.surfline.com/surf-news/maldives-surf-access-controversy-update_75296/

Cope, M. (2010). Coding transcripts and diaries. In N. Clifford, S. French \& G. Valentine (Eds.), Key methods in geography (pp. 440-452). London: SAGE.

Deats, J., Martinez, M., Shearer, R., \& Shearer, W. (2016). The tragedy of the waves. Sport, Business and Management, 6, 97-105.

de Rijke, K., Munro, P., \& de Lourdes, M. M. Z. (2016). The Great Artesian Basin: A contested resource environment of subterranean water and coal seam gas in Australia. Society \& Natural Resources, 29(6), 696-710.

Derkyi, M., Ros-Tonen, M. A. F., Kyereh, B., \& Dietz, T. (2014). Fighting over forest: Toward a shared analysis of livelihood conflicts and conflict management in Ghana. Society and Natural Resources, 27, 281-298.

Dolnicar, S., \& Fluker, M.R. (2003). Behavioural market segments among surf tourists: investigating past destination choice. Journal of Sport Tourism 8, 186-196.

Dunn, K. (2010). Interviewing. In I. Hay (Ed.), Qualitative research methods in human geography (pp. 101-138). South Melbourne: Oxford University Press.

Dyer, M. (2016). Eating money: Narratives or equality on customary land in the context of natural resource extraction in the Solomon Islands. The Australian Journal of Anthropology, doi: 10.1111/taja.12213.

Easthope, H., Hudson, S., \& Randolph, B. (2013). Urban renewal and strata scheme termination: balancing communal management and individual property rights. Environment and Planning A, 45, 1421-1435.

Gerring, J. (2007). Case study research: Principles and practices. New York: Cambridge University Press.

Goulding, C., Shankar, A., \& Canniford, R. (2013). Learning to be tribal: facilitating the formation of consumer tribes. European Journal of Marketing, 47, 813-832.

Grainger, C. A., \& Costello, C. (2016). Distributional effects of the transition to property rights for a common-pool resource. Marine Resource Economics, 31, 1-26.

Hameed, I. (2014). Surf breaks and dive sites removed from boundary regulation. 5 March. Retrieved 6 June 2015, from Liveaboard Association of Maldives, http://www.liveaboardassociation.mv/news/view/e369853df766fa44e1ed0ff613f563bd 
Ho, P. (2013). In defense of endogenous, spontaneously ordered development: institutional functionalism and Chinese property rights. Journal of Peasant Studies, 40, 1087-1118.

Hutt, J. A., Black, K. P., \& Mead, S. T. (2001). Classification of surf breaks in relation to surfing skill. Journal of Coastal Research, 29, 66-81.

Jamal, M. M., \& Lagiewski, R. (2006). A bipolar view of island tourism planning. A case of Maldives Islands. EuroCHRIE Congress 24. Greece: Thessaloniki.

Jameel, A. (2015). Contract to develop Thanburudhoo resort annulled. 18 August. Retrieved 3 November 2015, from Haveeru Online, http://www.haveeru.com.mv/business/61633

Kerr, S., Colton, J., Johnson, K., \& Wright, G. (2015). Rights and ownership in sea country: Implications of marine renewable energy for indigenous and local communities. Marine Policy, 52, 108-115.

Kundur, S. K. (2012). Development of Tourism in Maldives. International Journal of Scientific and Research Publications, 2(4), 1-5.

Lamb, S. (2012). Serendipity [DVD]. Xtreme Video, London.

https://www.youtube.com/watch?v=EI6hTbYvTFI

Lamers, M., Nthiga, R., van der Duim, R., \& van Wijk, J. (2014). Tourism-conservation enterprises as a land-use strategy in Kenya. Tourism Geographies, 16, 474-489.

Lazarow, N. (2009). Using observed market expenditure to estimate the value of recreational surfing to the Gold Coast, Australia. Journal of Coastal Research, 56, 1130-1134.

Lee, S. (2015). Research note: Quality of government and tourism destination competitiveness. Tourism Economics, 21, 881-888.

Leung, Y.F., Spenceley, A., Hvenegaard, G., \& Buckley, R.C. (2016). Tourism and Visitor Management in Protected Areas: Guidelines for Sustainability. IUCN, Gland. 269 pp.

Lucrezi, S., Saayman, M., \& Van der Merwe, P. (2015). Managing beaches and beachgoers: Lessons from and for the Blue Flag award. Tourism Management, 48, 211-230.

LUEX. (2014). Current Maldives situation: Freedom to surf or private waves? 14 October. Retrieved 20 January 2015, from LUEX Magazine, http://www.luex.com/magazine/2014/10/14/current-maldives-situation-freedom-to-surf-orprivate-waves/

Maldives Finest. (2015). Israeli tourist attack Maldivian at surf point. 12 September. Retrieved 3 November 2015, from Maldives Finest, http://www.maldivesfinest.com/israelitourists-attack-maldivian-at-surf-point

Manning, R. E. (2007). Parks and carrying capacity: Commons without tragedy. Washington: Island Press. 
Martin, S. A., \& Assenov, I. (2012). The genesis of a new body of sport tourism literature: A systematic review of surf tourism research (1997-2011). Journal of Sport \& Tourism, 17, 257-287.

Matilainen, A., \& Lähdesmäki, M. (2014). Nature-based tourism in private forests:

Stakeholder management balancing the interests of entrepreneurs and forest owners? Journal of Rural Studies, 35, 70-79.

Mixon, F. G. (2014). Bad vibrations: new evidence on commons quality and localism at California’s surf breaks. International Review of Economics, 61, 379-397.

Moffat, K., Lacey, J., Zhang, A., \& Leipold, S. (2016). The social licence to operate: a critical review. Forestry, 89, 477-488.

MoT. (2014). Resort boundary regulation 2014/R-18. Ministry of Tourism, Republic of Maldives, Male.

MoT. (2015a). Resort boundary regulation 2015/R-126. Ministry of Tourism, Republic of Maldives, Male.

MoT. (2015b). Tourism yearbook 2015. Ministry of Tourism, Republic of Maldives, Male. Retrieved 22 February 2016, from: http://www.tourism.gov.mv/statistics/annual-publications/

MSA. (2012). Thamburudhoo impact prediction. Maldivies Surfing Association, Male Retrieved 12 June 2015, from:

http://www.surfersvillage.com/img/st/thamburudhoo_impact_1.pdf

MTAC. (2012a). Fourth tourism master plan 2013-2017. Ministry of Tourism, Arts and Culture, Male.

MTAC. (2012b). Lagoon zoning regulation R-17/2012. Ministry of Tourism, Arts and Culture, Male.

MTAC. (2012c). Resort boundary regulation R-7/2012. Ministry of Tourism, Arts and Culture, Male.

MTAC. (2013). Tourism yearbook 2013. Ministry of Tourism, Arts and Culture, Male Retrieved 3 November 2015, from: http://www.tourism.gov.mv/pubs/Yearbook_2013.pdf

MTAC. (2015). Regulation governing foreign tourist vessels cruising and harbouring in Maldivian waters. Section 24 of Law No. 2/99 Maldives Tourism Act. Ministry of Tourism, Arts and Culture, Male. Retrieved 1 April 2016, from:

http://www.tourism.gov.mv/downloads/vessel_regulations/Foreign_Vessel_Regulation_eng.p df

Mull, J. (2012). Maldives controversy. 13 September. Retrieved 10 June 2015, from Surfer Magazine, http://www.surfermag.com/features/maldives-controversy/ 
Mull, J. (2013). The perils of privatization. An update on the proposed privatization of lineups in the Maldives. Retrieved 12 June 2015, from Surfer Magazine, http://www.surfermag.com/features/perils-privatization/

Mullen, J. \& Ullah, Z. (2015). Maldives declares State of Emergency, citing security threat. http://edition.cnn.com/2015/11/04/asia/maldives-state-of-emergency/

Murtazashvili, I., \& Murtazashvili, J. (2016). The origins of private property rights: states or customary organizations? Journal of Institutional Economics, 12, 105-128.

Naafiz, A. (2016). Maldives surfers protest losing 'lifeline' over bridge. 29 February.

Retrieved 1 March 2016, from Haveeru Online,

http://www.haveeru.com.mv/news/66909?e=en_mid

Navarro-Jurado, E., Mihaela-Damian, I., \& Fernandez-Morales, A. (2013). Carrying capacity model applied in coastal destinations. Annals of Tourism Research, 43, 1-19.

Naseer A. (2006). Pre-and post-tsunami coastal planning and land-use policies and issues in the Maldives. p. 55-80. In: Broadhead J.S. and Leslie R.N. (eds). Proceedings of the workshop on coastal area planning and management in Asian tsunami-affected countries. Bangkok: FAO.

NBS. (2015). Statistical yearbook of Maldives 2015. Retrieved 23 February 2016, from National Bureau of Statistics, http://planning.gov.mv/yearbook2015/index.html

Nelsen, C., Cummins, A., \& Tagholm, H. (2013). Paradise lost: threatened waves and the need for global surf protection. Journal of Coastal Research, 65, 904-908.

Nettle, S. (2012). Maldives close out: Sultans and Honkys to become exclusive resort waves. Retrieved 12 June 2015, from Swellnet, http://www.swellnet.com/news/surfpolitik/2012/08/15/maldives-close-out-sultans-andhonkys-become-exclusive-resort-waves

Nettle, S. (2014). Sultans and Honkeys open to all surfers. 28 April. Retrieved 3 November 2015, from Swellnet, http://www.swellnet.com/news/surfpolitik/2014/04/28/sultans-andhonkys-open-all-surfers

O'Brien, D., \& Ponting, J. (2013). Sustainable surf tourism: A community centered approach in Papua New Guinea. Journal of Sport Management, 27, 158-172.

Øian, H., \& Skogen, K. (2016). Property and possession: Hunting tourism and the morality of landownership in rural Norway. Society \& Natural Resources, 29, 104-118.

Omar, Y. A., Pretzsch, J., \& Darr, D. (2015). Land use conflicts in central Sudan: Perception and local coping mechanisms. Land Use Policy, 42, 1-6.

Ostrom, E. (2015). Governing the Commons. Cambridge University Press. 
Pierson, D. (2016). Protesting surfers arrested in Maldives. http://www.surfline.com/surfnews/construction-of-a-bridge-threatens-to-ruin-one-of-the-archipelagos-best-waves-localsup-in-arms-protesting-sur_136343/ Accessed 4 Aug 2016.

Ponting, J. \& O’Brien, D. (2014). Liberalizing Nirvana: an analysis of the consequences of common pool resource deregulation for the sustainability of Fiji's surf tourism industry. Journal of Sustainable Tourism, 22, 384-402.

Punch, K. F. (2014). Introduction to social research: Quantitative and qualitative approaches. London: SAGE.

Reed, M. S., Graves, A., Dandy, N., Posthumus, H., Hubacek, K., Morris, J., Prell, C., Quinn, C. H., \& Stringer, L. C. (2009). Who's in and why? A typology of stakeholder analysis methods for natural resource management. Journal of Environmental Management, 90(5), 1933-1949.

Rifaey, R. (2012). Surf exclusivity. Retrieved 17 August 2016, from scribd.com/doc/103025320/Surf.Exclusivity.

Riptide. (2016a). Bodyboarders arrested for surfing in The Maldives. 16 March. Retrieved 16 March 2016, from Riptide Magazine, https://riptidemag.com.au/2016/03/16/bodyboardersarrested-for-surfing-in-maldives/

Riptide. (2016b). Paradise lost in The Maldives. 8 March. Retrieved 16 March 2016, from Riptide Magazine, https://riptidemag.com.au/2016/03/08/paradise-lost-in-the-maldives/

Roxas, B., \& Chadee, D. (2013). Effects of formal institutions on the performance of the tourism sector in the Philippines: The mediating role of entrepreneurial orientation. Tourism Management, 37, 1-12.

Sattar, A. R. A. (2016). Save Our Waves: why we protest. 2 March. Retrieved 21 March 2016, from Maldives Independent, http://maldivesindependent.com/feature-comment/saveour-waves-why-we-protest-122557

Saunders, L. (2013). Be one of just 35 surfers riding exclusive waves in the beautiful Maldives. 8 November. Retrieved 3 May 2015, from Gold Coast Bulletin, http://www.goldcoastbulletin.com.au/lifestyle/be-one-of-just-35-surfers-riding-exclusivewaves-in-the-beautiful-maldives/story-fnjdow5o-1226755973152

Save Thanburudhoo. (2012). Save Thanburudhoo. Retrieved 19 May 2015, from Avaaz Community Petitions, https://secure.avaaz.org/en/petition/Say_NO_to_surf_exclusivity_in_the_Maldives

Save Thanburudhoo. (2013). End exclusivity - Save Thanburudhoo. 26 November, 14:56. Retrieved 20 January 2015, from Youtube, https://www.youtube.com/watch?v=idi4geKDmE

Scarfe, B.E., Healy, T.R. \& Rennie, H.G. (2009). Research-based surfing literature for coastal management and the science of surfing - a review. Journal of Coastal Research 253, 539-557. 
Scheyvens, R. (2011). The challenge of sustainable tourism development in the Maldives: Understanding the social and political dimensions of sustainability. Asia Pacific Viewpoint, 52, 148-164.

Scorse, J., Reynolds, F., \& Sackett, A. (2015). Impact of surf breaks on home prices in Santa Cruz, CA. Tourism Economics, 21, 409-418.

Shakeela, A., \& Becken, S. (2015). Understanding tourism leaders' perceptions of risks from climate change: An assessment of policy-making processes in the Maldives using the social amplification of risk framework (SARF). Journal of Sustainable Tourism, 23(1), 65-85.

Shakeela, A., Becken, S., \& Johnston, N. (2014). Gaps and disincentives that exist in the policies, laws and regulations which act as barriers to investing in climate change adaptation in the tourism sector of the Maldives. Maldives Ministry of Tourism, Republic of Maldives, 108 pp. Retrieved 3 November 2015, from:

http://www.tourism.gov.mv/downloads/publications/GapsAndDiscentives.pdf

Shakeela, A., Ruhanen, L., \& Breakey, N. (2011). The Maldives: A sustainable tourism success story? e-Review of Tourism Research, 9(5).

Shakeela, A., \& Weaver, D. (2012). Resident reactions to a tourism incident: Mapping a Maldivian Emoscape. Annals of Tourism Research, 39, 1337-1358.

Shenk, J. (2011). The Island President [DVD] Actual Films, San Francisco.

Sikor, T., He, J., \& Lestrelin, G. (2017). Property rights regimes and natural resources: a conceptual analysis revisited. World Development, doi: 10.1016/j.worlddev.2016.12.032

Slaev, A. D. (2016). The relationship between planning and the market from the perspective of property rights theory: A transaction cost analysis. Planning Theory, doi:

$10.1177 / 1473095216668670$

Sténs, A., \& Sandström, C. (2013). Divergent interests and ideas around property rights: The case of berry harvesting in Sweden. Forest Policy and Economics, 33, 56-62.

Surf Atoll. (2014). Thamburudhoo: Free access to everybody! Retrieved 4 July 2015, from Surf Atoll, http://www.surfatoll.com/2014/03/27/thamburudhoo/

Surfer Today. (2015). No more surf exclusivity at Maldives' Thanburudhoo Island. 17 August. Retrieved 6 November 2015, from Surfer Today, http://www.surfertoday.com/surfing/12082-no-more-surf-exclusivity-at-maldivesthanburudhoo-island

Temperley, E. (2014). Maldives retreat on wave privatization. 18 March. Retrieved 3 November 2015, from Magicseaweed, http://magicseaweed.com/news/maldives-retreat-onwave-privatisation/6196/ 
Thanburudhoo Resort. (2013). Managed surf program - Licenses. Retrieved 3 February 2015, from Thanburudhoo Resort, http://www.thanburudhoo.com/licensees.html No longer available since March 2015.

Towner, N. (2016a). Searching for the perfect wave: profiling surf tourists who visit the Mentawai Islands. Journal of Hospitality and Tourism Management, 26, 63-71.

Towner, N. (2016b). Community participation and emerging surfing tourism destinations: a case study of the Mentawai Islands. Journal of Sport and Tourism, 20, 1-19.

Towner, N. \& Orams, M. (2016). Perceptions of surfing tourism operators regarding sustainable tourism development in the Mentawai Islands, Indonesia. Asia Pacific Journal of Tourism Research. Doi: 10.1080/10941665.2016.1140663

Usher, L.E., Goff, J., \& Gomez, E. (2016). Exploring surfers’ perceptions of municipal regulations using grounded theory. Annals of Leisure Research, 19, 98-116.

Usher, L.E., \& Kerstetter, D. (2015). Re-defining localism: An ethnography of human territoriality in the surf. International Journal of Tourism Anthropology, 4, 286-302.

Veal, A. J. (2011). Research methods for leisure and tourism: A practical guide. Essex: Prentice Hall.

Wan, Y. K. P., \& Bramwell, B. (2015). Political economy and the emergence of a hybrid mode of governance of tourism planning. Tourism Management, 50, 316-327.

Webster, C., Wu, F., Zhang, F., \& Sarkar, C. (2016). Informality, property rights, and poverty in China's “favelas”. World Development, 78, 461-476.

Wells, K. (2011). Narrative inquiry. New York: Oxford University Press.

Williams, D. R. (2001). Sustainability and public access to nature: Contesting the right to roam. Journal of Sustainable Tourism, 9, 361-371.

World Surfaris. (2015). Hudhuranfushi surf resort. Retrieved 27 November 2015, from World Surfaris, http://www.worldsurfaris.com/surf-trip/hudhuranfushi-surf-resort

Xu, S., Liu, Y., Qian, Y., \& Wang, Q. (2017). The significance of the West Lake pattern and its heuristic implications for creating China's heritage tourism economics. Tourism Management, 58, 286-292.

Zigzag (2016). Zigzag.co.za/featured/for-rich-surfers-only-local-maldivian-surfers-rightsfurther-restricted/

Zubair, S., Bowen, D., \& Elwin, J. (2011). Not quite paradise: Inadequacies of environmental impact assessment in the Maldives. Tourism Management, 32, 225-234. 
